\title{
An investigation of the influence of a fiber arrangement of a laminate on the values of stresses in the composite panel of a modified freight wagon using the FEM method
}

\author{
Andrzej Buchacz, Andrzej Baier, Krzysztof Herbuś*, and Piotr Ociepka \\ Institute of Engineering Processes Automation and Integrated Manufacturing Systems, Faculty of \\ Mechanical Engineering, Silesian University of Technology, Konarskiego 18a, 44-100 Gliwice, \\ Poland
}

\begin{abstract}
In the work is presented the investigation of influence of fiber arrangement of a laminate on the values of stresses in the composite panel of a modified freight wagon using the FEM method. The conducted investigations concerned the reduced part of a side panel of a freight wagon. On this panel were mounted the tested composite panels. For this purpose, a special screw connection with a blind rivet nut was used. The first stage of works included manufacturing of a composite material consisting of four layers of a laminate. Each layer of the laminate is a composition of epoxy resin and carbon fibers with a plain weave in which fibers strands are woven at the angle of $90^{\circ}$. In the next step it was changed the main angle of placement of fibers in all layers of the laminate. Wherein, all layers of the laminate were characterized with the same angle of fibers with respect to the global coordinate system used in the numerical test. As a result of the study it was observed the relationship between the main angle of fibers of the composite material and the values of stresses occurring in the composite plate.
\end{abstract}

\section{Introduction}

In recent years it is observed a dynamic growth in the use of composite materials in various technical fields. One of the major types of used composite materials is the composite material reinforced with fibers. In these materials the matrix acts as a binder for the fibers. This allows joining the fibers together within a composite layer as well as the individual layers within the multilayer composite material. In the fiber materials [1-2] as the reinforcing phase are used various kinds of fibers. The most commonly used fibers are: glass fibers, graphite ones and carbon ones. While, as the matrix various types of resins are used, among which it could be mentioned: epoxy resin, phenolic one, polyester one, nylon one and polycarbonate one.

The increased interest in composite materials implies the creation of tools that could be used, already in virtual testing phase, to verify the application of composite structures in the analyzed field of problems. One such tool is PLM Siemens NX software [3-11], which

* Corresponding author: krzysztof.herbus@polsl.pl 
supports the process of designing and construction verification in terms of the motion dynamics and also stress analysis as well as production preparation.

Within the conducted investigations [12-15] realized by the research team and concerning the implementation of the project which objective is to extend the exploitation time of wagons between intervals associated with their regeneration it was decided to use, for this purpose, composite panels reinforced with fibers. The main task of the modernized freight wagons is to transport cargo in the form of loose or aggregate material (stone, hard coal, gravel). Both at the loading and unloading of transported cargo it comes to frequent damage of the inner shell of the wagon body. The resulting damage is of the mechanical nature. The main problem in this case is the phenomenon of decreasing in the thickness of the shell plate of the wagon body as a result of its abrasion. This attrition is of a stochastic nature. Another type of mechanical damage of the metal sheet is a result of the impact of an actuator of the loading (unloading) machine. In the body plating occur plastic deformations as the result of these actions. Another analyzed issue, considered with the plating damage, was the problem of an aggressive type of a cargo. The result of chemical interactions between transported materials and the plating of the wagon body are also local defects of the plate. The diagnosed dangers, in relation to freight wagons exploitation, were the basis for selection of composite material reinforced with fibers. As the matrix was used epoxy resin, and in the case of fibers there were used fiberglass and carbon fiber.

This paper presents studies on the application of the composite material which is a composition of epoxy resin and carbon fiber fabric. Such chosen composite material has a high resistance to abrasion, with high susceptibility and general chemical resistance. For the purpose of virtual testing the part of the modified wagon wall of the $418 \mathrm{~V}$ type was extracted (Figure 1).

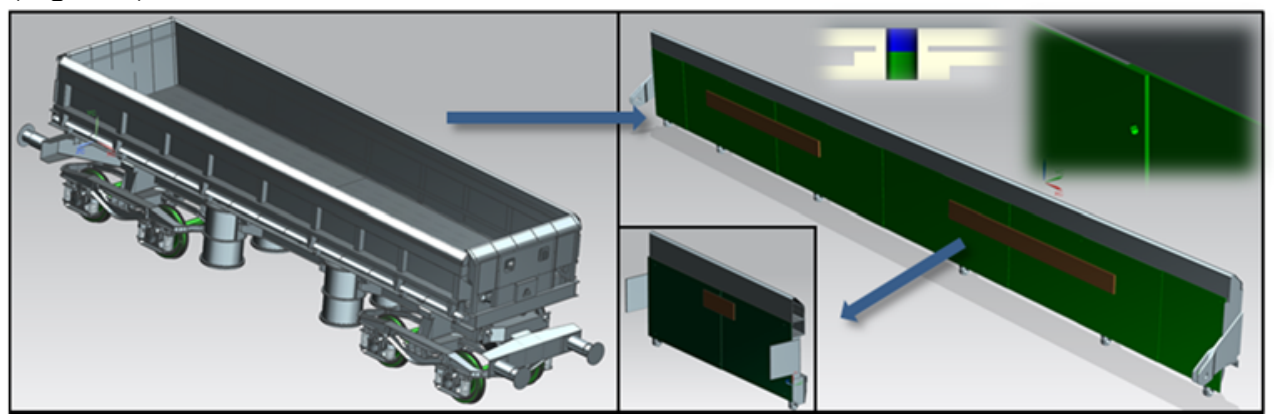

Fig. 1. Extracting of the part of the side wall of the freight wagon of the $418 \mathrm{~V}$ type.

The method used for extraction was such determine to ensure the possibility of elaboration the physical test stand and to improve the process of performing the numerical stress analysis and of their validation [14]. The adjusting of the FEM numerical model of the side wall of the wagon consisted of such model modifications to obtain the matching of calculated results and with the results of experimental tests (strain gauge ones). The matched model of the side wall of the wagon was the base for numerical analysis, using the FEM method, of the modernized freight wagon. In this case, to the FEM model was added the plates of composite material and it was analyzed values of stresses and displacements in relation both to the entire side wall and the composite panels themselves.

\section{Definition of the composite material}

The used composite material was the composite one consisting of four layers. Each layer of the composite material was a composition of the epoxy resin and carbon fiber with a plain 
weave, in which the fibers are woven at the angle of $90^{\circ}$. In Figure 2 is shown the structure of the used composite material.

The axes $\mathrm{x}, \mathrm{y}, \mathrm{z}$ represent the global coordinate system, in relation to which the analysis was performed using the finite element method. The axis 1 represents the orientation of fibers of the weft, and the axis 2 represents the orientation of fibers of the warp of the fabric woven of carbon fibers. Wherein the angle between the fibers of warp and of weft is always constant and is equal to $90^{\circ}$.

The individual layers of the composite material are arranged along the y axis. However, as the main direction of the fibers was assumed the $\mathrm{z}$ axis. In the case, when the orientation of fibers of the weft of the fabric woven of carbon fiber (1) coincides with the main direction of fibers arrangement $(\mathrm{z})$, the angle $\theta=0^{0}$. In any other case the angle $\theta \neq 0^{0}$.

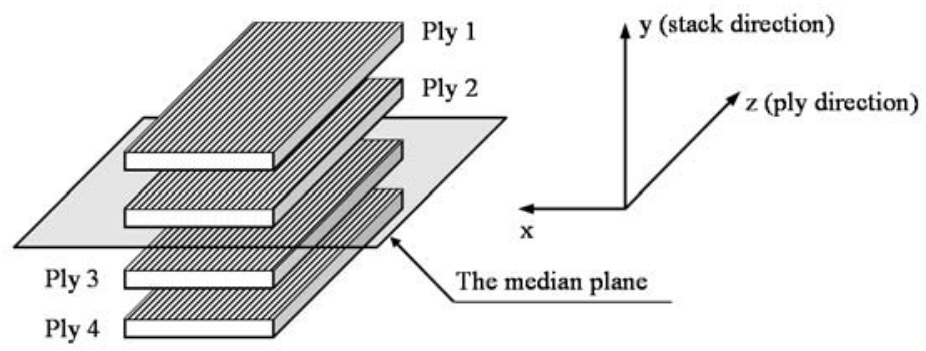

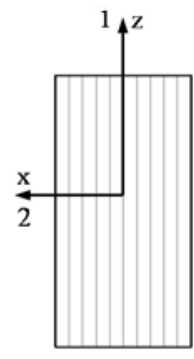

$\theta=0^{\circ}$

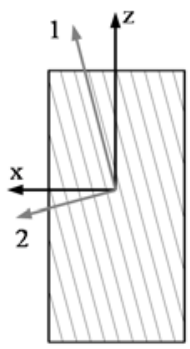

$\theta=15^{\circ}$
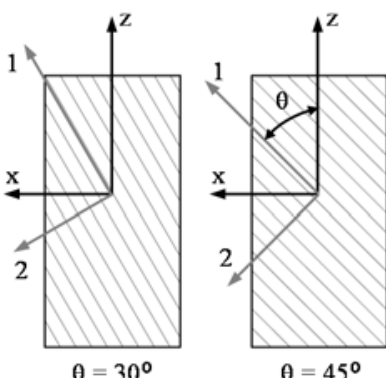

$\theta=45^{\circ}$

Fig. 2. The structure of the composite material.

It was assumed that all layers, within the composite material, are characterized by the same angle of fibers arrangement $\theta$, in relation to the main direction of fibers arrangement $(\mathrm{z})$. Therefore it was defined the four composite materials, which structure corresponds to the structure shown in Figure 1, with the angles $\theta$ respectively $0^{\circ}, 15^{\circ}, 30^{\circ}, 90^{\circ}$ (all four layers, within a single composition of the composite material, have the same angle of fibers arrangement). To conduct the numerical tests, using the FEM method, it was implemented the presented structure of composite material in the PLM Siemens NX program.

The applied epoxy resin has the following basic (standard) properties [12]: mass density $1300\left[\mathrm{~kg} / \mathrm{m}^{\wedge} 3\right.$ ], Young's modulus 3000 [MPa], Poisson's ratio 0.37 . Whereas the used carbon fabric has the following basic features: mass density $1770\left[\mathrm{~kg} / \mathrm{m}^{\wedge} 3\right]$, Young's modulus 240000 [MPa], Poisson's ratio 0.22.

One layer of the composite material has the following properties: matrix material - epoxy, matrix volume fraction -0.66 , warp fiber material - carbon fiber, weft fiber material - carbon fiber, fiber volume fraction -0.34 , balance coefficient -0.5 , weft fiber angle -90 degrees, Young's modulus $1-44240$ [MPa], Young's modulus $2-44240$ [MPa], Young's modulus 3 - 3000 [MPa], Poisson's ratio $12-0.032$, Poisson's ratio $13-0.344$, Poisson's ratio $23-$ 0.344 , shear modulus $12-1649$ [MPa], shear modulus $13-1047$ [MPa], shear modulus 23 $-879[\mathrm{MPa}]$, mass density $-1460\left[\mathrm{~kg} / \mathrm{m}^{\wedge} 3\right]$, thickness $-1[\mathrm{~mm}]$. 


\section{FEM analysis of the modified side of the freight wagon}

The conducted investigations concerned the reduced part of a side panel of a freight wagon. On this panel were mounted the tested composite panels. For this purpose, a special screw connection with a blind rivet nut was used.

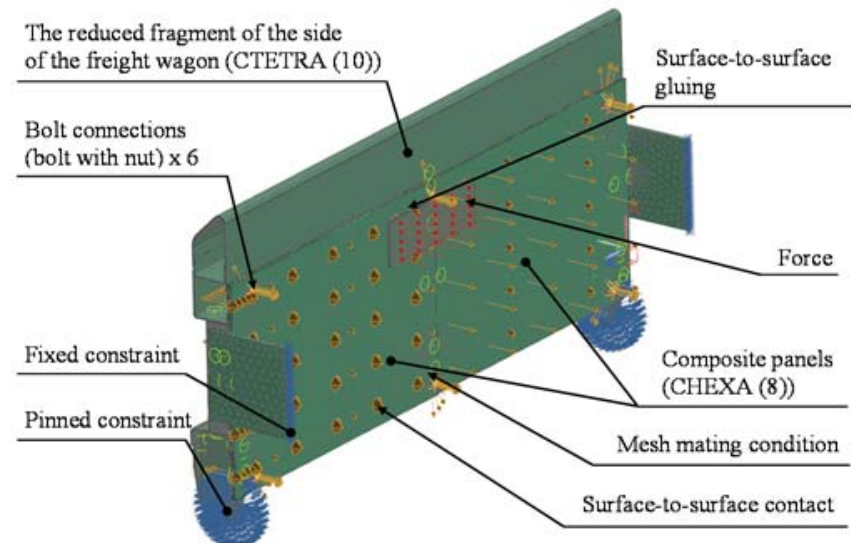

Figure 3. The model of the reduced fragment of the side of the freight wagon prepared to the FEM analysis.

The numerical investigations were performed in the PLM Siemens NX software. In the first step, it was created a mesh of finite elements of the steel elements of the side wall of the wagon. In this case was used finite elements of the CTETRA type (10 nodes tetragonal finite elements). Next was defined the mesh of finite elements with respect to the composite panels. In this case it was used finite elements of the CHEXA type ( 8 nodes hexagonal finite elements). To all elements of the plating of the freight wagon was assigned the same material steel.

While, with regard to the mounted composite panels, it was used, the previously defined and described, composite material. In the next step, the following boundary conditions were defined in relation to the analyzed issue (Figure 3): Fixed and pinned constraint - mapping the method of mounting of the of side wall of the wagon; Mesh mating condition - between elements of the wagon plating, which are permanently connected one to another; Surface-tosurface contact - between elements that are coming in contact under the load in the system (between the wagon plating and composite panels); Surface-to-surface gluing - between the composite panel and the beam, by which the load is transferred to the system and Bolt connections - mapping the method of joining the composite panels and the wagon plating.

On the basis of such prepared model it was conducted a series of strength tests using the FEM method. The particular, virtual experiment referred to a specific $\theta$ angle. However, in all tests it was assumed the constant value of the force acting on the analyzed system equal to $20[\mathrm{kN}]$.

In Figure 4 is shown the distribution of reduced stresses in the layer with the maximal effort of the composite material in relation to the $\theta$ angle of fibers arrangement and the distribution of displacements in relation to the entire system. On the Figure 4 are presented the maps of stresses and displacements in two extreme cases $\left(\theta=0^{\circ}, \theta=45^{\circ}\right)$.

While, in the Table 1 are gathered the values of the maximal reduced stresses in the particular layers of the composite material. In the mentioned Table also are shown the maximal displacements in relation to the entire system.

According to the presented stress distribution it could be observed the phenomenon of stress concentration in the areas in which there is a screw connection of the composite panel with the wagon side wall plating (Figure 4). 


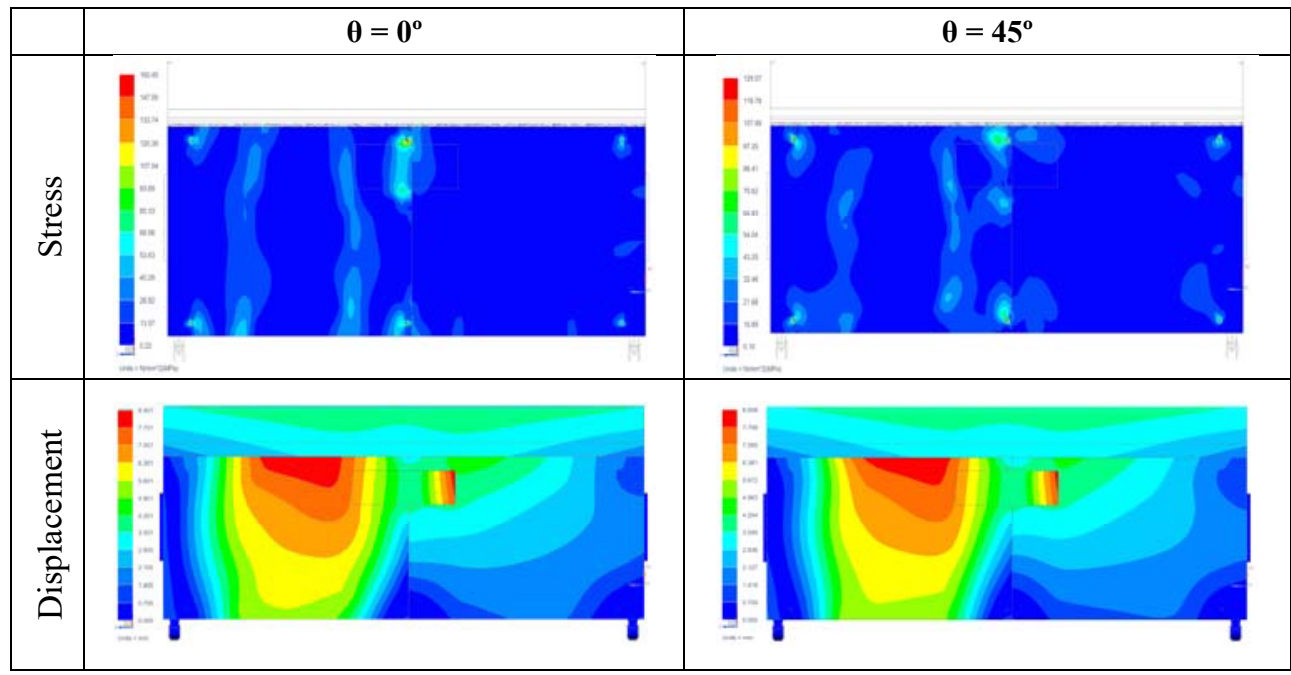

Fig. 4. Distribution of stresses in the layer, in which are the highest reduced stresses and distribution of displacements in relation to the entire system.

This phenomenon is very dangerous due to the possibility of mechanical damage of the outer layers of the composite panel under the influence of the axial force acting in the screw joint. This force is necessary to properly mount the composite panels to the side wall of the wagon.

Table 1. The maximal values of the reduced stresses (Von-Mises) in the ply of the composite panel and the value of the displacement.

\begin{tabular}{|c|c|c|c|c|}
\hline Stress [MPa] & $\boldsymbol{\theta = \mathbf { 0 } ^ { \mathbf { 0 } }}$ & $\boldsymbol{\theta = \mathbf { 1 5 } ^ { \mathbf { 0 } }}$ & $\boldsymbol{\theta}=\mathbf{3 0}^{\mathbf{0}}$ & $\boldsymbol{\theta}=\mathbf{4 5}^{\mathbf{}}$ \\
\hline Ply1 & 160 & 163 & 145 & 130 \\
\hline Ply2 & 80 & 73 & 68 & 68 \\
\hline Ply3 & 97 & 95 & 97 & 96 \\
\hline Ply4 & 163 & 169 & 149 & 138 \\
\hline $\begin{array}{c}\text { Displacement } \\
\text { [mm] }\end{array}$ & 8.4 & 8.45 & 8.5 & 8.5 \\
\hline
\end{tabular}

On the basis of the obtained results it could be concluded that the highest values of reduced stresses are in the layer 1 and 4. While, much smaller values of reduced stresses are in the two middle layers (ply2 and ply3).

In accordance with the obtained values it could be said that there is a correlation between the values of the stresses occurring in the layers of the composite material and the angle of arrangement of the weft fibers of the fabric woven of carbon fiber. When the fibers of the weft in the fabric of carbon fiber are placed at the angle $\theta=45^{\circ}$ in relation to the main direction of the fibers it was observed the decrease of reduced stresses in the extreme layers of the composite panel by $19 \%$. However, in the case of ply 2 the decrease of stress values was equal to $15 \%$. In the case of ply 3 there was no significant decrease in stress values.

The maximum absolute displacement measured on the composite plate is equal to 8.5 $\mathrm{mm}$. The composite panel in the neutral position (without load) is spaced from the metal paneling of the wagon by the value of $5.2 \mathrm{~mm}$. If the load is applied along the y axis, first the composite panel is pushed to the paneling of a wagon and then will move along together with the wagon wall $(5.2 \mathrm{~mm}+3.3 \mathrm{~mm}=8.5 \mathrm{~mm})$. 


\section{Conclusions}

In the result of the conducted investigations it was observed the relationship between the $\theta$ angle of arrangement of the weft fibers of the fabric of carbon fibers and the values of stresses occurring in the particular layers of the composite panel. In the case of the composite material which is the composition of epoxy resin and carbon fibers with a plain weave, in which the fiber strands are woven at the angle of $90^{\circ}$, the lowest values of stresses in the composite layers was observed when the angle $\theta=45^{\circ}$. Wherein, all tests were carried out under identical boundary conditions.

On this basis it was determined the most preferred method of assembly (because of the angle of arrangement of the weft fibers of the fabric) the composite panels to the side panel of the wagon to minimize stresses occurring in the composite plate. Furthermore, the proposed arrangement of the fibers reduces the unfavorable influence of the mechanical reaction of the joining elements on the values of stresses in the outer layers of the composite material.

\section{References}

1. R. Martinsa, L. Reisa, R. Marat-Mendesa, Procedia Structural Integrity, 1, 066-073 (2016)

2. J. Bienias, H. Dębski, B. Surowska, T. Sadowski, Computational Materials Science, 64, 168-172 (2012)

3. W. Banaś, K. Herbuś, G. Kost, A. Nierychlok, P. Ociepka, D. Reclik, Advanced Materials Research, 837, 537-542 (2014)

4. K. Herbuś, P. Ociepka, IOP Conf. Series: Materials Science and Engineering, 95, 012096 (2015)

5. A. Dymarek, T. Dzitkowski, K. Herbuś, G. Kost, P. Ociepka, Advanced Materials Research, 837, 351-356 (2014)

6. P. Ociepka, K. Herbuś, IOP Conf. Series: Materials Science and Engineering, 95, 012101 (2015)

7. K. Herbuś, G. Kost, D. Reclik, J. Świder, Advanced Materials Research, 837, 582-587 (2014)

8. K. Herbuś, P. Ociepka, IOP Conf. Series: Materials Science and Engineering, 95, 012084 (2015)

9. P. Ociepka, K. Herbuś, IOP Conf. Series: Materials Science and Engineering, 95, 012100 (2015)

10. K. Herbuś, P. Ociepka, IOP Conf. Series: Materials Science and Engineering, 145, 042018 (2016)

11. K. Herbuś, P. Ociepka, IOP Conf. Series: Materials Science and Engineering, 145, $052010(2016)$

12. A. Buchacz, A. Baier, K. Herbuś, M. Majzner, P. Ociepka, Applied Mechanics \& Materials, 809/810, 944-949 (2015)

13. M. Płaczek, A. Wróbel, A. Baier, IOP Conf. Series: Materials Science and Engineering, 95, $012042(2015)$

14. A. Buchacz, A. Baier, J. Świder, M. Płaczek, A. Wróbel, K. Herbuś, P. Ociepka, W. Banaś, M. Sobek, Ł. Grabowski, M. Majzner, Analytical and experimental tests and determination of characteristics of components working as assemblies of innovative structures of repaired freight cars (Wydawnictwo Politechniki Śląskiej, Gliwice 2016)

15. A. Buchacz, A. Baier, K. Herbuś, M. Majzner, P. Ociepka, Springer Proceedings in Mathematics \& Statistics, Dynamical Systems: Modelling, 181, 97-105, (2016) 